\title{
WARNA ALAMI DARI EKSTRAK TANAMAN KOPI ROBUSTA
}

\author{
Susi Susyanti ${ }^{1}$ \\ (Institut Teknologi Sumatera, susi.susyanti111@gmail.com, susi.susyanti@dkv.itera.ac.id, 087727935644) \\ Okta Amelia ${ }^{2}$ \\ (Teknologi , Institut Teknologi Sumatera, okta.amelia@tin.itera.ac.id) \\ Muhammad Hajid An Nur ${ }^{3}$ \\ (DKV, Institut Teknologi Sumatera, hajid.annur@dkv.itera.ac.id) \\ PG Wisnu Wijaya ${ }^{4}$ \\ (DKV, Institut Teknologi Sumatera, wisnu.wijaya@dkv.itera.ac.id)
}

\begin{abstract}
Color is a supportive part of visual emotion for connoisseurs and users. Colors can be enjoyed if assisted with good lighting. The color in this study discusses natural dyes. Natural dyes used are natural ingredients robusta coffee plants taken from the plateau of Liwa, West Lampung, Indonesia. Natural dyes that have been obtained then made a group pallet from the extract of coffee plants in the form of liquid and staining to the fabric. The method used is staining with the extraction process and a variation of mordanting using the fixation of alum. This color palette can be worn and used by anyone to create color branding or a prodak that wants to display robusta coffee images. Also done testing TLW (wet \& asam) and the level of the color of the age. It is to know the quality of fabric from the staining if you want to make disposable products such as fashion.
\end{abstract}

Keywords: natural color, palette, robusta coffee

\section{ABSTRAK}

Warna merupakan bagian pendukung emosi visual bagi penikmat maupun pengguna. Warna dapat kita nikmati jika dibantu dengan pencahayaan yang baik. Warna pada penelitian ini membahas mengenai pewarna alami. Pewarna alami yang dipakai adalah bahan alam tanaman kopi robusta yang diambil dari dataran tinggi Liwa, Lampung Barat, Indonesia. Pewarna alami yang sudah didapatkan kemudian dibuat palet kelompok dari hasil ekstrak tanaman kopi berupa cairan dan dilakukan pewarnaan terhadap kain. Metode yang digunakan adalah pewarnaan dengan proses ekstraksi dan variasi mordanting menggunakan fiksasi tawas. Palet warna ini dapat dipakai dan digunakan oleh siapapun untuk membuat color branding maupun suatu produk yang ingin menampilkan image kopi robusta. Dilakukan juga pengujian (Tingkat Luntur Warna) TLW (basah \& asam) dan tingkat ketuaan warna. Hal tersebut untuk mengetahui kualitas kain dari hasil pewarnaan jika akan dibuat produk pakai, sepertifashion.

Kata Kunci: palet, warna alam, kopi robusta

\section{PENDAHULUAN}

Sebagai salah satu negara yang mempunyai kekayaan sumber daya alam yang cukup melimpah, Indonesia merupakan negara yang sangat potensial dalam penyediaan bahan baku bersumber dari alam. Namun pada kenyataannya, sumber daya alam yang dimiliki belum dikelola dengan maksimal kendati secara 
tradisional pengelolaannya telah dilakukan oleh nenek moyang terdahulu. Alama mengajarkan kita selain untuk bertahan hidup salah satunya dalah memenuhi kebutuhan estetika. Tidak sedikit karya atau produk yang dibuat manusia semata-mata meniru bentuk dan fungsi mahluk hidup lain seperti, hewan maupun tumbuhan (biomimikri). Sehingga benar menurut pernyataan (Hidayati.N.N, 2015) bahwa alam semesta dan dinamikanya menyimpan hal yang menarik untuk diamati dan direnungkan.

Pewarna alami diambil dari hasil ekstrak jenis-jenis flora, fauna, bahkan mineral dan logam. Geografis pun ikut memengaruhi hasil ekstrak bahan alam tersebut. Sumber daya alam Indonesia mempunyai potensi untuk memperkaya koleksi warna alami. Warna alami daun jati dataran tinggi belum tentu sama dengan daun jati dataran rendah. Pemetaan warna alami dari tiap-tiap sumber daya alam menjadi langkah yang efektif untuk memperkaya koleksi warna alami Indonesia. Peta warna ini tidak hanya digunakan untuk ranah tekstil namun juga pangan, maupun color branding.

Warna juga merupakan tampilan visual yang menambah kesan pendukung emosi bagi para penikmatnya, maupun pemakainya. Pembahasan warna pada penelitian ini ialah terkait pewarna alami. Pewarna alami yang akan banyak dibahas adalah pewarna alami yang diambil dari jenis tanaman kopi robusta khas Lampung. Mengapa pewarna alam, hal ini merupakab salah satu upaya mengurangi penggunaan pewarna sintetis yang merugikan ligkungan. Seperti yang diupayakan oleh Sedjati.D.P, (2019-2020) penggunaan zat pewarna alam sebagai upaya mengurangi pencemaran lingkungan akibat penggunaan zat warna sintetis.

Lampung salah satu penghasil kopi robusta cukup terkenal dengan kualitasnya. Kopi pada umumnya sebagai minuman, kemudian berkembang ke arah kecantikan salah satunya sebagai masker wajah dan lulur, bentuk dari tanaman kopi pun dijadikan inspirasi motif pada tekstil, pengharum ruangan, tidak sedikit pula yang memanfaatkan pada ampas kopi, sehingga semua bagian dari kopi menjadi menarik untuk diteliti. Begitupula dari ranah visual seperti warna yang eksotis dari kopi belum dipetakan sebagai warna khas jenis kopi robusta di Lampung dengan karakter geografis yang dimiliki sebagai pewarna alami pangan maupun nonpangan.

Salah satu kekayaan flora yang tumbuh subur yaitu kopi. Kopi Robusta (coffea canephora) memiliki berbagai bagian dari akar hingga limbah yang dihasilkan dari proses olah kopi. Salah satu limbah dari pengolahan biji kopi yaitu cangkang kopi. Jika dilihat dari morfologi tanaman kopi yaitu memiliki akar, batang, daun, bunga, buah Juliansyah. D, (2015:7)

Warna alami yang biasa digunakan dan umum diketahui hanya bagian-bagian kecilnya saja. Banyak tulisan beredar namun hanya membahas salah satu atau dua dari satu tanaman tertentu, Seperti pewarna ekstrak kayu nangka oleh Rosyida dkk (2013), akar mengkudu oleh Farida dkk (2015), ekstrak biji buah pinang oleh Prabawa I.D.G.P (2015), ekstraksi kelopak bunga rosella oleh Mahfud (2015), pewarna daun ketapang-daun mahonibunga kecombrang oleh Kumalasari (2016), dan ekstraksi pigmen cangkang kepiting oleh Nasriani (2018). Sejauh ini belum ada yang mengupayakan pengelompokan peta warna pada satu jenis tanaman utuh secara digital. Warna alami dari hasil ekstrak pada kain maupun larutan akan didigitalisasikan sehingga mudah mencari kesan warna tanaman kopi menggunakan color image scale by Kobayashi (2013).

Proses pewarnaan memerlukan peran mordan. Mordan disini membantu warna nabati menempel pada serat yang dicelupkan (Fox.A, 2015:13). Proses ekstraksi tanaman kopi dilakukan dengan cara perebusan bahan baku 
yang kemudian ditransfer warnanya pada kain katun. Proses ini adalah yang paling ideal dalam mentransfer pigmen pada kain. Seperti yang yang telah dilakukan oleh (Mayliana.E, 2016) bahwa tahap terakhir adalah fiksasi, yaitu tahap yang dilakukan pada kahir proses pewarnaan yang berfungsi mengunci warna supaya warna tidak mudah lepas. Artinya mengunci disini ialah setelah pigmen warna meresap sempurna pada kain dikunci dengan fiksasi supaya warna tidak keluar dari serat kain atau luntur terkena air pada proses pencucian selanjutnya. Setelah semua pembuatan sampel berhasil dilakukan, kemudian dilakukan pengamatan warna yang terikat pada kain. Tujuannya untuk mengetahui kesan warna yang terkandung dalam tanaman kopi melalui proses ekstraksi dengan fiksasi tawas maupun nonfiksasi lewat media kain menggunakan panduan buku Color Index by Jim Krause (2007) dan Color Image scale by Kobayashi (2013).

Penggolongan mood warna telah dilakukan pada penelitian yang sejenis sebelumnya. Selanjutnya pada pembahasan kali ini lebih kepada hasil uji lab pada kain yang telah diwarnai. Hal ini bertujuan untuk mencari tahu efek tingkat luntur pada kain, sehingga ketika kain akan diproduksi secara massal sudah memiliki data yang akurat terkait warna standarnya.

\section{METODE}

Bahan penelitian warna alam berupa tanaman kopi robusta (coffea canephora), tawas, dan air. Peralatan yang digunakan adalah Kain, pisau, gunting, saringan, pengaduk, timbangan, perebus air, gelas ukur pyrex, Adobe Ilustator CS6, dan buku Color Index by Jim Krause (2007), buku Color Image scale by Kobayashi S. (1990).

Proses ekstraksi yang digunakan dalam penelitian ini adalah metode ekperimen dengan tiga perlakuan untuk 12 sampel. Perlakuan yang digunakan adalah free-mordant, pra-mordant dan simultan. Fiksasi yang dipakai adalah tawas, mordanting, dan pewarnaan masing-masing dilakukan selama 30 menit dengan larutan tawas. Keduabelas sample bahan baku warna alami melewati free-mordant, pra-mordant dan simultan, yaitu: Akar,Kayu, Kulit Kayu, Ranting, Daun Segar, Daun Kering, Kulit Buah, Kulit Tanduk Segar, Kulit Tanduk Kering, Biji Segar, Biji Kering, Bubuk Kopi.

\section{HASIL DAN PEMBAHASAN}

\section{a. 12 palet warna alami dari tanaman kopi robusta}

Hasil pewarnaan alami pada kain ditampilkan dalam bentuk warna digital. Hal ini adalah upaya dalam mempermudah pembaca digital yang ingin menggunakan warna alami secara digital supaya lebih mudah. Belakangan banyak desainer-desainer tekstil yang bergerak dimedia digital namun tetap ingin menggunakan tone/mood hasil pewarna alami sebagai inspirasi warna untuk karya yang diciptakan, maka dengan adanya palet warna digital warna alami ini menjadi lebih banyak eksplorasi karya.

Hasil klasifikasi 12 bagian-bagian tanaman kopi robusta mengasilkan 36 sample warna dari hasil ekstrak berupa cairan. Hasil berupa cairan ini merupakan hasil ekstrak yang direkomendasikan untuk mewarnai kain, makanan, minuman, dan warna untuk menggambar pada bidang gambar kertas (sebagai pengganti cata air). Hasil ke-36 warna lainnya yaitu pewarnaan pada kain, kali ini sudah masuk ranah pewarna alami untuk tekstil melaluui proses panas atau direbus.

Jika dijabarkan lagi, maka dari tiap sample bahan pewarna alam misalkan (akar). Hasil ekstrak akar digunakan untuk pewarnaan pada kain dengan tiga fariasi free-mordant, pramordant dan simultan, maka kemudian akan menghasilkan tiga kain dan air dari sisa pewarnaan tiga fariasi tersebut. Sehingga satu sampel bahan baku pewarna alami menghasilkan enam warna, tiga warna dari kain dan tiga dari air. Untuk dapat mempermudah dalam membaca hasil warna alami tanaman kopi maka dibuat palet semacam diagram yang 
berangkat dari pohon kopi seperti pada tampilan di bawah.

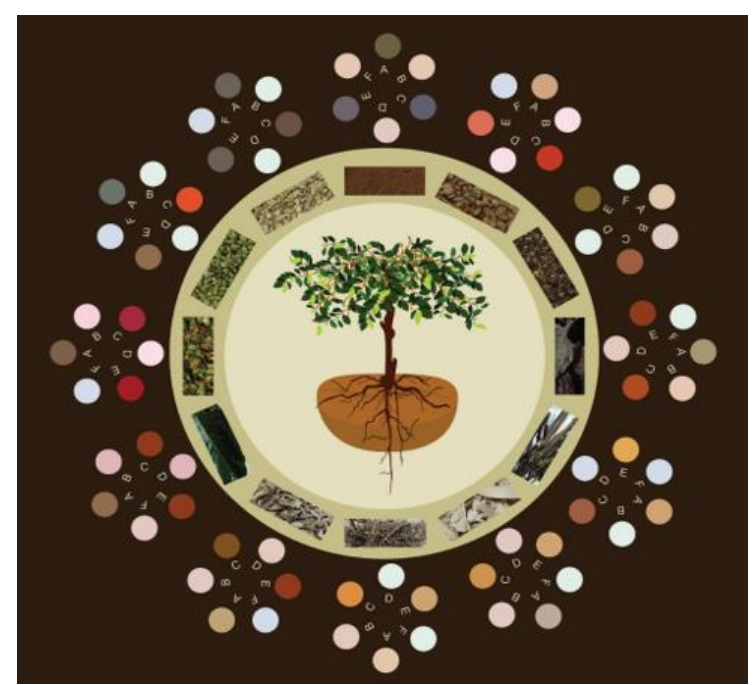

Gambar 1. 12 palet warna alami kopi robusta (coffea canephora)

Seperti pada gambar di atas. Terdapat duabelas lingkaran yang memiliki enam dot warna yang terdiri dari $A, B, C, D, E$ dan $F$. Bagian tengan merupakan penggambaran dari batang tubuh tanaman kopi robusta yang menjadi bahan baku pewarna alami. Terdiri dari duabelas klasifikasi yang ditampilkan pada lingkaran berikutnya berbentuk gambar persegi panjang yang mengelilingi pohon kopi. Terdapat gambar akar dipaling bawah kemudian kekanan gambar kayu, ke kiri gambar kulit kayu, kanan ranting, kiri daun segar, kanan daun kering, kiri kulit buah, kanan kulit tanduk segar, kiri kulit tanduk kering, kanan biji segar, kiribiji kering, dan paling sisi atas bubuk kopi. Setiap gambar langsung terdapat lingkaran paling luar yaitu enam warna A-F. Yang mana; Warna air freemordant, Warna kain free-mordant, Warna air pra-mordant, Warna kain pra-mordant, Warna air simultan, Warna kain simultan.

Dapat diperhatikan bahwa ternyata warna air lebih pekat daripada warna pada kain. Karena dikemas dalam warna digital, sehingga warna yang diperoleh sangat kaya. Dan warna dengan fiksasi selain tawas misalkan, cuka, tunjung, soda kue memungkinkan akan menghasilkan warna yang berbeda-beda, Begitulah istimewanya pewarna alam .

\section{b. Kecenderungan Warna dari Tiap Sample}

Setelah berhasil membuat pengelompokan warna pada gambar.1, selanjutnya dilakukan pengambilan data atas kecenderungan warna yang sedang diminati atau sedang trend pada saat penelitian berlangsung. Warna yang telah dihasilkan melalui eksperimen pada kain kemudian dilakukan pengujian TLW (Tingkat Luntur Warna). Namun sebelum itu dilakukan terlebih dahulu kuesioner untuk mengambil duabelas dari 72 warna, data hasil kuesioner dapat dilihat pada diagram 1.

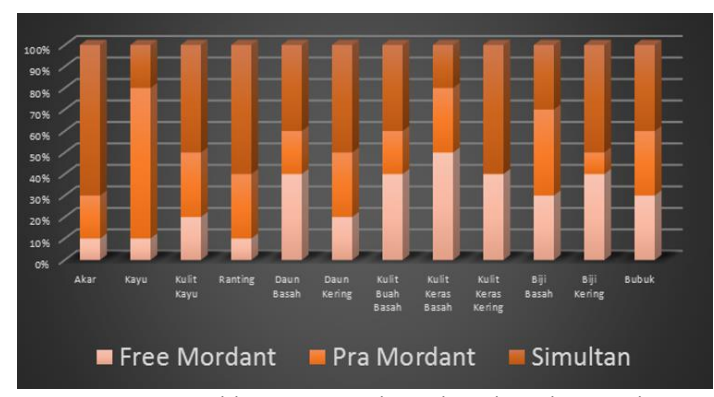

Diagram 1. Hasil kuesioner ekstrak pohon kopi robusta (coffea canephora)

Berdasarkan data pada diagram $1 \mathrm{di}$ atas, bisa ditarik kesimpulan bahwa kecenderungan warna yang dipilih oleh narasumber adalah warna dari hasil pewarnaan variasi simultan. Warna dari variasi free mordant dan pra mordant memiliki nilai yang seimbang seperti pada diagram 2 berikut.

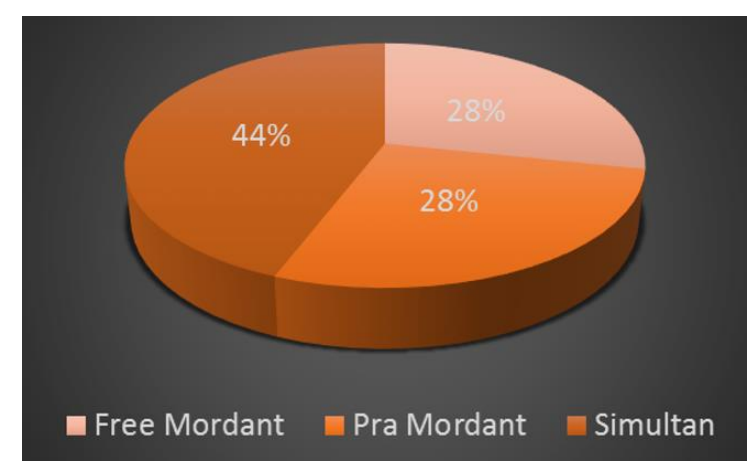

Diagram 2. Hasil kuesioner ekstrak pohon kopi robusta (coffea canephora)

Sehingga bisa diketahui, trend dan kecenderungan saat ini yaitu warna-warna hasil 
pewarnaan proses simultan. Sehingga dapat dijadikan sebagai tolak ukur dalam pembuatan produk untuk menentukan warna yang sedang diminati pasaran terkait pewarna alami dari tanaman kopi robusta.

\section{c. Pengujian TLW terhadap keringat (basah \& asam) dan ketuaan warna kain}

Perlunya dilakukan pengujian lab untuk mengetahui Tingkat Luntur Warna (TLW). Hal ini adalah salah satu langkah untuk mendapatkan hasil yang terukur jika suatu saat terdapat produk tekstil yang menerapkan pewarna alam kopi robusta. Sebab pewarna alami sangat sensitive terhadap zat-zat lainnya, seperti kimia berbahaya maupun tidak. Sehingga perlu diketahui kelemahankelemahan yang dimilki tekstil berbahan dan berwarna alami untuk menghindari hal-hal yang tidak diinginkan.

Telah dilakukan pengujian TLW (Tingkat Luntur Warna) terhadap keringat (basah \& asam) pada kain dan uji ketuaan warna pada kain (refleksi=R\%) masing-masing dua belas sampel. Pengujian ketuaan warna menggunakan program UV-PC model ISR-2200. Hasil uji dapat dilihat pada tabel berikut:

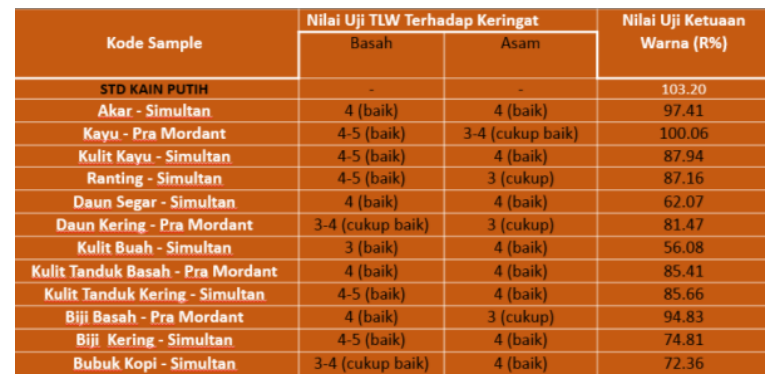

Tabel 2. Data Hasil Uji Lab. Evaluasi Tekstil (pengujian TLW terhadap keringat (basah \& asam) dan pengujian Ketuaan Warna Kain (R\%)

Dapat dilihat pada tabel 2 di atas. Ternyata kain dengan pewarnaan selain daun kering-pra mordant dan bubuk kopi simultan mendapat hasil baik, artinya dalam keadaan keringat basah kain ini layak dikenakan. Namun terdapat hampir empat kain pewarnaan kayupra mordan, ranting-simultan, daun kering-pra mordant dan biji basah-simultan sebaiknya tidakdirekomendasikan untuk pengguna tekstil yang memiliki keringat dengankadar asam. Sedangkan dari duabelas kain yang diujikan terdapat satu sampel kain dengan pewarnaan kayu-pra mordant yang paling mendekati standar ketuaan warna diantara warna yang lain.

Sample yang dipakai adalah sample yang dominan dipilih dari sebaran kuesioner, sehingga tidak berangkat dari bahan pewarna dan variasi yang sejenis. Yang mendominasi variasi pewarnaan mordant adalah simultan dan ditambah dengan variasi pra mordant. Namun untuk bahan alam pewarna tanaman kopi robusta di ambil semua dari dua belas bagian untuk mencari kemungkikankemungkinan sample terbaik.

Dari akar diambil variasi simultan, kayu diambil variasi pra mordant, kulit kayu diambil variasi simultan, ranting diambil variasi simultan, daun segar diambil variasis simultan, daun kering diambil variasi pra mordant, kulit buah diambil variasi simultan, kulit keras buah basah diambil variasi pra mordant, kulit keras buah kering diambil variasi simultan, biji basah diambil variasi pra mordant, biji kering diambil variasi simultan, dan bubuk diambil variasi simultan.

\section{PENUTUP}

12 palet warna alami dari hasil ekstrak dan pewarnaan tanaman kopi jenis robusta yang samplenya di ambil dari dataran tinggi liwa lampung barat memiliki 6 dari tiap paletnya. 12 palet dibuat berdasarkan 12 sample bahan alami pewarnaan dari bagian-bagian tanaman kopi.

Selain membuat palet, kain hasil pewarnaanpun dilakukan pengujian lab untuk mengetahui tingkat kelunturan terhadap keringat basah dan asam, serta mengetahui tingkat ketuaan warna. Hal tersebut untuk mendapatkan data jika dikemudian hari pewarnaan alam kopi dengan metode mordanting ini akan dibuat masal, atau produksi bahan pakaian.

Dari ke-3 variasi mordanting menggunakan viksasi tawas, variasi simultan yang memiliki tingkat kepekatan warna yang baik terhadap kain. 12 palet warna alami yang sudah berupa warna digital dapat dipakai sebagai palet warna untuk pembuatan color branding suatu produk dengan image kopi robusta khas Lampung. 


\section{Daftar Pustaka}

\section{Artikel Jurnal}

Ainur Rosyida. 2013. Pewarnaan Bahan Tekstil dengan Menggunakan Ekstrak Kayu Nangka dan Teknik Pewarnaan untuk Mendapatkan Hasil yang Optimal: Jurnal Rekayasa Proses Vol 7 No. 2

Dadan Suherman. 2013. Menghilangkan Warna dan Zat Organik air Gambut dengan Metode Koagulasi Flokulasi suasana basah: Jurnal RISET geologi dan pertambangan Vol 23 No. 2 Desember 2013.

Djandjang Purwo Sedjati. 2019-2020. Keben (Barringtonia Asiatica), Motif dan Pewarna Batik: Jurnal Corak ISI Yogyakarta Vol 8 No. 2 2019-2020.

Ester Mayliana. 2016. Pengaruh Lama Waktu Mordanting Terhadap Ketuaan Warna dan Kekuatan Tarik Kain Mori dalam Proses Pewarnaan dengan Zat Pewarna Sabut Kelapa: Jurnal Corak ISI Yogyakarta Vol 5 No. 12016.

Farida Farida. 2015. Pengaruh Variasi Bahan Pra Mordan pada Pewarnaan Batik Menggunakan Akar Mengkudu (Morinda Citrifolia): Ejurnal kemenperint Vol 32 No. 1 2015.

I Dewa Gede Putra Pabawa. 2015. Ekstrak Biji Buah Pinang Sebagai Pearna Alami pad Kain Sasirangan: Jurnal Riset Industri Hasil Hutan Vol 7 No. 2 Desember 2015.

Irfa'ina Rohana Salma. 2015. Kopi dan Kakao dalam Kreasi MOTIF Batik Khas Jember: Jurnal Balai Besar Kerajinan Batik Vol 32 No. 2 Desember 2015.

Nasriani. 2018. Ekstraksi Pigmen Karotenoid pada Cangkang Kepiting sebagai Pewarna Alami yang Sehat: Jurnal IImiah UMG Vol 7 No. 12018.

Nuri Ningsih Hidayati. 2015. Motif Sakura Warna Alam pada Kain Pajang: Jurnal Corak ISI Yogyakarta Vol 4 No. 12015.
Tuatul Mahfud. 2015. Ekstrak Pewarna Alami Kelopak Bunga Rosella (Hibiscus Sabdariffa) pada Pembuatan Minuman Serbuk Instran Rosella: Jurnal Sains Terapan Vol 1 No. 1 Juni 2015.

\section{Buku}

Alice Fox. 2015. Natural Processes In Textile Art. Batsford: UK

Bambang Prastowo. 2010. Budi Daya dan Pasca Panen KOPI. Bogor: Pusat Penelitian dan Pengembangan Perkebunan.

Jim Krause. 2007. Color Index. HOW Books: Ohio.

Shigenobu Kobayashi. 2013. Color Image Scale. Kodansha: Japanese.

Skripsi, Thesis, Disertasi, dan Laporan Penelitian Dede Juliansyah. (2015). Budidaya Tanaman Kopi, UNS, Serang.

Olivia Laimena. (2018). Pusat Edukasi dan Rekreasi Kopi di Lampung Barat, UNIKA atma jaya, Yogjakarta. 